\title{
Exploring the Influence of Teacher-Student Interaction on University Students' Self-Efficacy in the Flipped Classroom
}

\author{
Lin $\mathrm{Li}^{1} \&$ Shanshan Yang ${ }^{1}$ \\ ${ }^{1}$ School of Business, Chengdu University, Chengdu, China \\ Correspondence: Lin Li, School of Business, Chengdu University, No. 2025, Chengluo Avenue, Chengdu City, \\ Sichuan Province, China. E-mail: 641008187@qq.com
}

Received: January 9, 2021 Accepted: February 12, 2021 Online Published: February 20, 2021

doi:10.5539/jel.v10n2p84 URL: https://doi.org/10.5539/jel.v10n2p84

\begin{abstract}
The purpose of this study is to explore the impact of teacher-student interaction on undergraduate students' self-efficacy in a Chinese university setting. Students came from natural science, management, economics, medicine, engineering and humanities. The empirical results demonstrate that teacher-student interaction has positive impact on students' self-efficacy and their preference of the flipped classroom. Furthermore, the positive relationship between teacher-student interaction and students' self-efficacy is partially mediated by students' preference of the flipped classroom. Educators should focus on student-centered learning and motivate students' preference of the flipped classroom. Students should be encouraged to actively participate in the flipped learning as well. It contributes to the reform of the flipped classroom and improvement of teaching quality in the universities.
\end{abstract}

Keywords: teacher-student interaction, self-efficacy, flipped classroom

\section{Introduction}

Rapid development of information technology has changed teaching and learning models. The flipped classroom has burgeoned. The literature indicates that the flipped classroom offers positive academic outcomes after a decade of research (Chen et al., 2017; Brewer \& Movahedazarhouligh, 2018). It is concluded that the flipped classroom can not only improve students' learning performance and promote their confidence, but also provide collaborative learning and peer-assisted learning to help students engage in the flipped model (Akcayir \& Akcayir, 2018). The flipped classroom is a student-centered teaching approach and philosophy that has challenged instructors to renew their teaching ideas and concept (He, 2014), and students to make the shift from passive learning to active learning as well. There has been a boom in the adoption of online education because of the global outbreak of COVID-19. One of the characteristics of the flipped classroom is that it combines the advantages of online and face-to-face instruction. Therefore, it will help to drive the sustainable and healthy development of online education.

However, researchers have demonstrated little interest in teacher-student interaction in the flipped classroom. Teacher-student relationship has been neglected in higher education study (Hagenauer \& Volet, 2014). Considering prior studies mainly focused on theoretical studies or subject-specific areas (Zhang, 2017), quantitative studies and cross-disciplinary studies may contribute to understanding teacher-student interaction. Consequently, the objective of this study is to analyze the influence of teacher-student interaction on university students' self-efficacy in the flipped classroom environment. The study will be beneficial to interdisciplinary researches of teacher-student interaction and harmonious relationship between university teachers and students.

\section{Literature Review}

Teacher-student interaction has been regarded as one of the critical issues in the higher education context. Learner-centered teacher-student relationship helps draw attention to the students and learning processes as critical to students' learning outcomes (Lambert \& McCombs, 1998; Cornelius-White, 2007). Relationship between teachers and students influences students' learning outcomes significantly (Zhang, 2019). Chickering and Gamson (1987) suggested that frequent faculty-student contact is the most important factor to motivate students in undergraduate education. Generally, active teacher-student interaction is positively related to students' academic and social success. The environments of teacher-student interaction have been changing because of the 
growing availability of internet and artificial intelligence technologies. Compared to traditional teaching, the flipped classroom is more complex and flexible in the component of teaching materials and processes.

The flipped classroom has different features in interactive subjects, contents, methods and stages. It provides active and good opportunities for interaction during teaching processes between teachers and students, and among students. According to Hosam et al. (2020), the utilization of flipped classroom promotes the students' engagement. The flipped approach was found to facilitate the interaction with the teachers and learners (Mzoughi, 2015). By high intensity interaction and collaborative learning forms, the flipped classroom can enhance the students' problem-solving ability and reinforce their sharing of ideas and involvement. Thus, it can stimulate their overall development (Feng et al., 2016). Zeng and Zhan's (2016) survey of teaching effects based on 2,739 students in undergraduate colleges stated that teaching models using new technologies such as the flipped classroom and MOOC can significantly improve the classroom teaching effect. The more, the better.

Yet, some scholars reported the inconsistency to the previous results. For example, there were no significant impacts of the flipped classroom on students' learning. Compared to traditional classroom, the flipped classroom cannot improve students' grades, achievement, and performance (Davies et al., 2013; Hotle \& Garrow, 2015; Ojennus, 2016). Further research should explore how the flipped classroom can affect the students' learning outcomes. Specifically, this study focuses the following two research questions:

1) How are teacher-student interaction and students' self-efficacy correlated to each other in the flipped learning context?

2) What is the effect of students' preference of the flipped classroom between teacher-student interaction and students' self-efficacy?

\section{Research Hypotheses}

\subsection{Teacher-Student Interaction and University Students' Self-Efficacy}

In the flipped classroom, teacher-student interaction consists of online interaction and classroom interaction. Online interaction between teachers and students, characterized by person-machine-person relationship, presents as human domination. It has numerous advantages, which utilizes multiple technological methods to break the time and space limitation. Despite these views, online interaction may not replace classroom interaction (Yang et al., 2010). The flipped learning was found to facilitate students to become active learners and participants, while teachers acted as instructors and promotors as well (He, 2017). The utilization of flipped classroom can help students internalize and transfer knowledge through affective interaction with teachers and peers in the classroom, thus reducing students' cognitive load (Ye et al., 2014).

Self-efficacy has been used in higher education to study students' learning approaches (Richardson et al., 2012). In the flipped classroom, self-efficacy, which is a psychological factor affecting learners' performance and success, is influenced by several factors. Online and classroom interactions between teachers and students provide considerable learning resources for the students, while teachers can solve the problems online or in the classroom. They improve the frequency and efficiency of teacher-student communication, and contribute to students to take charge of their own learning process. For example, they can pause or rewind media resources to review or revisit the learning materials (Bergmann \& Sams, 2012). Hence, teacher-student interaction may reinforce students' belief or confidence to complete their tasks. Thus, we propose:

Hypothesis 1. Teacher-student interaction in the flipped classroom is positively related to university students' self-efficacy.

\subsection{Teacher-Student Interaction and Students' Preference of the Flipped Classroom}

Because of interaction between teaching and learning, teacher-student interaction is known to be a complex process. A national survey in Chinese colleges and universities found that there were several prominent problems in interactions of classroom teaching (Zhang, 2019). For instance, teachers could not remind students of their learning problems and requirements, or provide immediate feedback to students' assignments. Consequently, traditional teacher-centered teaching approach would not be accepted by the students. Conversely, the flipped classroom transforms teacher-centered teaching into student-centered teaching. The flipped approach supports knowledge teaching by offering opportunities for students' autonomy and self-directed learning. Face-to-face teaching encourages students' involvement as group discussion, cooperative learning, and presentation activities and problem solving. Students are motivated to participate in the teacher-student interaction, which they can obtain effective and objective feedback. Obviously, students prefer the flipped learning. Therefore, the following hypothesis is proposed: 
Hypothesis 2. Teacher-student interaction is positively related to university students' preference to the flipped classroom.

\subsection{The Mediating Role of Students' Preference of the Flipped Classroom}

Gen Z-ers are digital natives who are used to digital living style. In digital learning environments, university students are capable of learning new knowledge and professional skills with multiple IT means. The flipped classroom applies internet and information technology to break through traditional classroom and teaching. It facilitates teachers and students to improve their communication. Students can obtain access to online information and resources and finish learning assignments based on online course platforms, thus teacher-student interaction may be enhanced. Undoubtedly, teacher-student interaction in the flipped classroom context stimulates students' learning interest and motivation, so they become more active participants. Hence, students' preference leads to successfully strengthen their confidence in the learning. Based on the above argument, we posit the following hypothesis:

Hypothesis 3. University students' preference of the flipped classroom mediates the relationship between teacher-student interaction and students' self-efficacy.

\section{Method}

\subsection{Sample}

We collected data from a Chinese university that explores the flipped classroom as teaching reform. This university allowed us to randomly select undergraduates with the flipped learning experiences. From 2018 to 2019, we sent out 649 questionnaires to the students in the classes and collected them onsite. Among them, 463 ones were effective (71.3\% effective rate). Students were mostly female (73\%). $20.5 \%$ were freshmen, $67.4 \%$ were sophomore, and $7.6 \%$ were junior students. They came from economics $(17.1 \%)$, management $(46 \%)$, natural science (21.2\%), engineering (3.7\%), medicine (8.9\%) and humanities (3.2\%).

\subsection{Measures}

In this study, we selected Fisher et al.'s (1998) 48-item teacher-student interpersonal behavior scale, which was revised by Xin (2000), to measure teacher-student interaction. The scale consists of eight dimensions as leadership, helping, understanding, student responsibility, uncertain, dissatisfied, admonishing, and strict behaviors. Each of the eight subscales contains six items. We calculated the scores of all items. Students rated each item in a five-point scale ranging from 0 , "never", to 4, "always". Two sample items are "This teacher explains things clearly" and "We can decide something in this teacher's class".

Self-efficacy was measured using a ten-item general self-efficacy scale (GSES) developed by Schwarzer et al. (1997). Students rated each item on a four-point scale ranging from 1, "not at all true", to 4, "exactly true". Sample items are "It is easy for me to stick to my aims and accomplish my goals" and "I can solve most problems if I invest the necessary effort". Students' preference of the flipped classroom using one-item on a five-point scale ranging from 1 , "strongly dislike", to 5 , "strongly like".

Control variables such as students' gender, grade, and major were collected and controlled for, given that they may correlate with study variables and have relations between study variables.

\section{Results}

\subsection{Confirmatory Factor Analysis}

To ensure that we could assess teacher-student interaction as a higher order factor, we conducted a confirmatory factor analysis with Amos. The model showed the acceptable fit $\left(\chi^{2}=48.067, \mathrm{df}=6, \chi^{2} / \mathrm{df}=8.011 \mathrm{RMR}=\right.$ 0.009 , GFI $=0.974, \mathrm{NFI}=0.979$, TLI $=0.915, \mathrm{CFI}=0.982 ;$ Kline, 2005). The model of self-efficacy demonstrated the acceptable fit $\left(\chi^{2}=258.193, \mathrm{df}=35, \chi^{2} / \mathrm{df}=7.377, \mathrm{RMR}=0.037, \mathrm{GFI}=0.891, \mathrm{NFI}=0.851\right.$, $\mathrm{TLI}=0.83, \mathrm{CFI}=0.868$; Kline, 2005).

\subsection{Descriptive Statistics and Correlation Analysis}

Table 1 displays means, standard deviations, correlations, and Cronbach alpha coefficients of the studied variables. It is noted that teacher-student interaction was significantly correlated with university students' self-efficacy $(r=0.33, p<0.01)$ and students' preference of the flipped classroom $(r=0.14, p<0.01)$; students' preference of the flipped classroom and their self-efficacy were significantly correlated $(r=0.14, p<$ 0.01 ). These results provide initial support for above hypotheses. 
Table 1. Means, standard deviations, and correlations of all variables

\begin{tabular}{llllllll}
\hline Variables & $\mathrm{M}$ & $\mathrm{SD}$ & 1 & 2 & 3 & 4 & 5 \\
\hline 1. Gender & 0.27 & 0.44 & & & & & \\
2. Grade & 1.97 & 0.70 & $-0.13^{* * *}$ & & & & \\
3. Major & 8.22 & 3.33 & -0.09 & $0.33^{* *}$ & & & \\
4. TS interaction & 1.88 & 0.40 & $0.25^{* *}$ & -0.04 & $-0.10^{*}$ & $(0.894)$ & \\
5. Self-efficacy & 2.33 & 0.51 & $0.16^{* *}$ & -0.02 & -0.07 & $0.33^{* *}$ & $(0.868)$ \\
6. Preference & 3.27 & 0.81 & $0.11^{*}$ & -0.04 & -0.09 & $0.14^{* *}$ & $0.14^{* *}$ \\
\hline
\end{tabular}

Note. TS interaction=teacher-student interaction. Gender: $0=$ female; $1=$ male. Grade: $1=$ freshman; $2=$ sophomore; $3=$ junior; $4=$ senior; $5=0$ other Major: 1=philosophy; 2=economics; $3=$ law; 4=education; $5=$ literature; $6=$ history; $7=$ natural science; $8=$ engineering; 9=agriculture; $10=$ medicine; $11=$ management; $12=$ arts. Cronbach alpha coefficients are reported in parentheses on the diagonal.

$* \mathrm{p}<0.05, * * \mathrm{p}<0.01, * * * \mathrm{p}<0.001$ (two-tailed).

\subsection{Reliability Analysis and Common Method Bias Analysis}

As shown in Table 1, all the variables demonstrated internal consistency with acceptable coefficient alphas, which were higher than the suggested cutoff value of 0.70 (Nunnally \& Bernstein, 1994). As in this study using self-report data, common method bias may have affected the survey results (Podsakoff et al., 2003). We conducted common variance test with SPSS. The first factor extracted by principal component analysis explained $20.57 \%$ of the variance of all variables, lower than $50 \%$ (Hair et al., 1998). Thus, we limited the effects of common method variance.

\subsection{Test of Hypotheses}

Before testing the hypotheses, independent sample t-test analyses were conducted to evaluate the impacts of gender on students' self-efficacy and preference. The results showed that there were statistically significant gender differences in students' self-efficacy and preference scores. Analysis results of variance showed that grade and major had significantly influences on students' self-efficacy. Meanwhile, the results of multicollinearity test indicated that the index of tolerance and variation inflation index met the standards. Then, we used hierarchical regression analysis to assess the relationships.

As shown in Table 2, after entering the control variables, gender, grade, and major, teacher-student interaction in the flipped classroom was positively related to students' self-efficacy $(b=0.40, p<0.001)$, and students' preference $(b=0.21, p<0.05)$. $\mathrm{H} 1$ and $\mathrm{H} 2$ were supported. According to the three-step procedure of testing the mediation model (Baron \& Kenny, 1986), the results of $\mathrm{H} 1$ and $\mathrm{H} 2$ met the first two requirements for mediation test. We thus entered students' preference to test the possible mediating effect on the relationship between teacher-student interaction and students' self-efficacy. Students' preference was found to be significantly related to self-efficacy $(b=0.06, p<0.05)$, while the coefficient of teacher-student interaction was reduced in size but still significant $(b=0.39, p<0.001)$, suggesting partial mediation. $\mathrm{H} 3$ was supported.

Table 2. Regression summary for the mediating role of students' preference

\begin{tabular}{llll}
\hline \multirow{2}{*}{ Variables } & Preference & \multicolumn{2}{l}{ Students' Self-efficacy } \\
\cline { 2 - 4 } & Model 1 & Model 2 & Model 3 \\
\hline Gender & 0.16 & 0.10 & 0.09 \\
Grade & $0.00^{*}$ & $-4.894 \mathrm{E}-6$ & $1.000 \mathrm{E}-5$ \\
Major & $2.811 \mathrm{E}-5^{* *}$ & $8.711 \mathrm{E}-6$ & $7.097 \mathrm{E}-6$ \\
TS interaction & $0.21^{*}$ & $0.40^{* * *}$ & $0.39 * * *$ \\
Preference & & & $0.06^{*}$ \\
$\mathrm{R}^{2}$ & $0.05^{*}$ & $0.12^{* * *}$ & $0.13^{* * *}$ \\
\hline
\end{tabular}

Note. TS interaction=teacher-student interaction. ${ }^{*} \mathrm{p}<0.05, * * \mathrm{p}<0.01,{ }^{* * *} \mathrm{p}<0.001$ (two-tailed).

\section{Conclusion and Discussion}

This study reports the effect of teacher-student interaction on university students' self-efficacy in the flipped classroom in China. Results and findings presented above show that teacher-student interaction could improve students' self-efficacy. Students' preference of the flipped classroom partially mediated the relationship of teacher-student interaction with their self-efficacy. Active teacher-student interaction could increase students' preference of the flipped classroom, thus enhance their self-efficacy as well. Hence, teacher-student interaction would have important impact on university students' self-efficacy in the flipped classroom. 
The findings of the present study offer support to explain the influence of teacher-student interaction on students' self-efficacy in a Chinese higher education setting. Positive teacher-student interaction can promote university students' self-efficacy. Compared to the traditional classes, the flipped classroom requires teachers and students to comply with student-centered approach. What is important with this finding is that teachers and students should be prepared for the transformation of student-centered education. Teachers should use information technology to direct, supervise and assist students' online and classroom learning, and subsequently motivate students' preference of the flipped classroom. On the other hand, students should be directly involved and active in the flipped learning to improve their learning outcomes.

We suggest teachers might focus on students with low self-efficacy levels to encourage them to participate in the flipped learning. Those with low self-efficacy should be provided with more support in comparison with high self-efficacy students. Through active teacher-student interaction, learning in the flipped classroom could enhance students' self-efficacy. Conversely, the enhanced self-efficacy will be conducive to the construction of harmonious teacher-student relationship. In addition, this could improve the reform of the flipped classroom and enhance students' learning outcomes.

This research has limitations. One significant limitation is the samples used. They came from one university. Moreover, this study undertook a limited mediating variable. Third, self-rating scales were used. Further research can be extended to diversified colleges and universities. Research can also explore other mediating variables or moderating variables to check how teacher-student interaction affects students' self-efficacy. Finally, research samples can be extended in several aspects in future study.

\section{Acknowledgements}

The study was carried out thanks to the support of the Industry-University Cooperative Education Project of the Ministry of Education of China (No. 201802058004) and Curriculum Ideology Project of Chengdu University.

\section{References}

Akçayır, G., \& Akçayır, M. (2018). The flipped classroom: A review of its advantages and challenges. Computers \& Education, 126, 334-345. https://doi.org/10.1016/j.compedu.2018.07.021

Al Samarraie, H., Shamsuddin, A., \& Alzahrani, A. I. (2020). A flipped classroom model in higher education: A review of the evidence across disciplines. Educational Technology Research and Development, 68(3), 1017-1051. https://doi.org/10.1007/s11423-019-09718-8

Baron, R. M., \& Kenny, D. A. (1986). The moderator-mediator variable distinction in social psychological research: Conceptual, strategic, and statistical considerations. Journal of Personality and Social Psychology, 51(6), 1173-1182. https://doi.org/10.1037/0022-3514.51.6.1173

Bergmann, J., \& Sams, A. (2012). Flip your classroom: Reach every student in every class every day. Washington, DC: International Society for Technology in Education.

Brewer, R., \& Movahedazarhouligh, S. (2018). Successful stories and conflicts: A literature review on the effectiveness of flipped learning in higher education. Journal of Computer Assisted Learning, 34(4), 409-416. https://doi.org/10.1111/jcal.12250

Chen, F., Lui, A. M., \& Martinelli, S. M. (2017). A systematic review of the effectiveness of flipped classrooms in medical education. Medical Education, 51(6), 585-597. https://doi.org/10.1111/medu.13272

Chickering, A. W., \& Gamson, Z. E. (1989). Seven principles for good practice in undergraduate education. Biochemical Education, 17(3), 140-141. https://doi.org/10.1016/0307-4412(89)90094-0

Cornelius-White, J. (2007). Learner-centered teacher-student relationships are effective: A meta-analysis. Review of Educational Research, 77(1), 113-143. https://doi.org/10.3102/003465430298563

Davies, R. S., Dean, D. L., \& Ball, N. (2013). Flipping the classroom and instructional technology integration in a college-level information systems spreadsheet course. Educational Technology Research and Development, 61(4), 563-580. https://doi.org/10.1007/s11423-013-9305-6

Feng, Z. H., Wu, W. C., \& Hu, X. Y. (2016). Research on the Coding of Classroom Interaction Analysis in the Flipped Classroom. Journal of Distance Education, 4, 59-64. Retrieved from https://kns.cnki.net $/ \mathrm{kcms} /$ detail $/$ detail.aspx? dbcode $=$ CJFD\&dbname $=$ CJFDLAST2016\&filename $=$ YCJY20 1604008\&v=kzmv5I3zKgmMdyZ2nyOn9Z0adeS0nW\%25mmd2BmSyv\%25mmd2BS1AKow6JTCRwSG POoZouZldeGG94 [Chinese]

Fisher, D., Kent, H., \& Fraser, B. (1998). Relationship between teacher-student interpersonal behaviour and 
teacher personality. School Psychology International, 19(2), 99-119. https://doi.org/10.1177/0143034398192001

Hagenauer, G., \& Volet, S. E. (2014). Teacher-student relationship at university: An important yet under-researched field. Oxford Review of Education, 40(3), 370-388. https://doi.org/10.1080/03054985.2014.921613

Hair, J. F., Anderson, R. E., Tatham, R. L., \& Black, W. C. (1998). Multivariate data analysis (5th ed.). Publication Upper Saddle River, NJ: Prentice Hall.

He, K. K. (2014). On the future development of flipped classroom in China: From the nature of flipped classroom. E-education Research, 7, 5-16. Retrieved from https://kns.cnki.net $/$ kcms/detail/detail.aspx? dbcode $=$ CJFD\&dbname $=$ CJFD2014\&filename $=$ DHJY2014070 02\& $=\% 25 \mathrm{mmd} 2 \mathrm{~Bq} 5$ PYQwkCaf9C0181 puCENdcX1g\%25mmd2B7uEe2Li1RHoi6\%25mmd2FH1PECqs 3nEQ8P1\%25mmd2B6dcH8X4 [Chinese]

He, Y. (2017). Research on college teacher-student interaction in MOOC and flipped classroom. Journal of Nanjing Medical University (Social Sciences), 3, 238-242. Retrieved from https://kns.cnki.net $/ \mathrm{kcms} /$ detail/detail.aspx? dbcode $=$ CJFD\&dbname $=$ CJFDLAST2017\&filename $=$ YKNS20 1703016\&v=QmsFPbk\%25mmd2FMZBvK0qTlx315ov5OnX4Vf93Kb21iFozM\%25mmd2BscAO6r17qku TPuUYYOIbCd [Chinese]

Hotle, S. L., \& Garrow, L. A. (2016). Effects of the traditional and flipped classrooms on undergraduate student opinions and success. Journal of Professional Issues in Engineering Education and Practice, 142(1), 05015005. https://doi.org/10.1061/(ASCE)EI.1943-5541.0000259

Kline, R. B. (2005). Principles and practices of structured equation modeling (2nd ed.). New York, NY: Guilford Press.

Lambert, N. M., \& McCombs, B. (Eds.). (1998). How students learn: Reforming schools through learner-centered education. Washington DC: American Psychological Association. https://doi.org/10.1037/10258-000

Mzoughi, T. (2015). An investigation of student web activity in a "flipped" introductory physics class. Procedia-Social and Behavioral Sciences, 191, 235-240. https://doi.org/10.1016/j.sbspro.2015.04.558

Nunnally, J. C., \& Bernstein, I. H. (1994). Psychometric theory (3rd ed.). New York, NY: McGraw-Hill.

Ojennus, D. D. (2016). Assessment of learning gains in a flipped biochemistry classroom. Biochemistry and Molecular Biology Education, 44(1), 20-27. https://doi.org/10.1002/bmb.20926

Podsakoff, P. M., MacKenzie, S. B., Lee, J. Y., \& Podsakoff, N. P. (2003). Common method biases in behavioral research: A critical review of the literature and recommended remedies. Journal of Applied Psychology, 88(5), 879-903. https://doi.org/10.1037/0021-9010.88.5.879

Richardson, M., Abraham, C., \& Bond, R. (2012). Psychological correlates of university students' academic performance: a systematic review and meta-analysis. Psychological Bulletin, 138(2), 353-387. https://doi.org/10.1037/a0026838

Schwarzer, R., BaBler, J., Kwiatek, P., Schroder, K., \& Zhang, J. X. (1997). The assessment of optimistic self-beliefs: Comparison of the German, Spanish, and Chinese versions of the General Self-efficacy Scale. Applied Psychology: An International Review, 46(1), 69-88. https://doi.org/10.1111/j.1464-0597.1997.tb01096.x

Xin, Z. Q., Lin, C. D., \& Yu, G. L. (2000). Preliminary revision and application of the questionnaire on teacher interaction. Journal of Psychological Science, 23(4), 404-407, 509. Retrieved from https: $/$ kns.cnki.net $/ \mathrm{kcms} /$ detail $/$ detail.aspx $?$ dbcode $=$ CJFD\&dbname $=$ CJFD2000\&filename $=$ XLKX2000040 $04 \& \mathrm{v}=\mathrm{C} 2 \mathrm{~L} \% 25 \mathrm{mmd} 2 \mathrm{Fqwhzo} 1 \% 25 \mathrm{mmd} 2 \mathrm{~F} \% 25 \mathrm{mmd} 2 \mathrm{FkEBV} 33 \mathrm{~S} \% 25 \mathrm{mmd} 2 \mathrm{BcHFa} 85 \mathrm{Dj} 46 \mathrm{IRaq} 8 \mathrm{DkaMkO}$ MUYbmLajzsk84KEzSY0zV5c [Chinese]

Yang, G., Xu, X. D., \& Xie, H. B. (2010). From classroom to internet: A multidisciplinary perspective study of interaction between teacher and student. Journal of Distance Education, 6, 46-52. Retrieved from https: $/$ /kns.cnki.net $/ \mathrm{kcms} /$ detail $/$ detail.aspx?dbcode $=$ CJFD\&dbname $=$ CJFD2010\&filename $=Y C J Y 2010060$ 14\&v=v1eVPK55PgIrbKsS91JYOoo\%25mmd2Bxb7OdMZUcTHIoFf8RhY3zdkfSxmHg0VFYN15eBP5 [Chinese]

Ye, D. L., Wang, K., Zeng, T., \& Mao, J. J. (2014). The effective research of teachers and students' interaction 
based on participatory courses in flipped classroom. Modern Educational Technology, 24(12), 77-83. Retrieved from https://kns.cnki.net $/ \mathrm{kcms} /$ detail/detail.aspx?dbcode $=$ CJFD\&dbname $=$ CJFDLAST2015\&filename $=$ XJJS201 412014\&v=5eLX5zyXBUYnIE8884Yseo5Q96QXrT2r8VO4PXWgm2yRNe\%25mmd2B7vLJvKK060dK ZGX\%25mmd2BC [Chinese]

Zeng, G. L., \& Zhan, L. (2019), An empirical study on the effect of new technologies on classroom teaching in colleges and universities. Jiangsu Higher Education, 9, 66-71. Retrieved from https://kns.cnki.net $/ \mathrm{kcms} /$ detail/detail.aspx?dbcode $=$ CJFD \&dbname $=$ CJFDLAST2019\&filename $=$ JSGJ201 909011\&v=q3rLIMMLV\%25 mmd2F4x6\%25mmd2FrlU3rxJNK66j71ugmincpgDS6tSkfkpnewosYoYD1j LSlHW\%25mmd2BSi [Chinese]

Zhang, J. H. (2019). The Current Situation and Effect of Teacher-Student Interaction in College Teaching. Research in Education Development, 23, 10-17. Retrieved from https://kns.cnki.net $/ \mathrm{kcms} /$ detail/detail.aspx $?$ dbcode $=$ CJFD $\&$ dbname $=$ CJFDLAST2020\& filename $=$ SHGJ20 1923005\&v=jWTRCL4fkFbrQjYk6OIaqBarBHwfDa4E2Wr\%25mmd2BwA7q\%25mmd2B8fMqJ6MkrPrg g0pAzO5XRXF [Chinese]

Zhang, X. Y. (2017). Research focus on teacher-student interaction in Chinese classroom. Journal of Wuhan Technical College of Communications, 19(4), 17-24, 75. Retrieved from https://kns.cnki.net/kcms/detail/detail.aspx?dbcode=CJFD\&dbname=CJFDLAST2018\& filename=JTGL201 704004\&v=1f8vlHDJeor635SJ1pVW39uDw\%25mmd2BPyppkX776uWANrEK\%25mmd2F27kTiKJv0Q MYv5tlZN1w1 [Chinese]

\section{Copyrights}

Copyright for this article is retained by the author, with first publication rights granted to the journal.

This is an open-access article distributed under the terms and conditions of the Creative Commons Attribution license (http://creativecommons.org/licenses/by/4.0/). 